\title{
A single-subject study of robotic upper limb training in the subacute phase for four persons with cervical spinal cord injury
}

\author{
Linda Sørensen ${ }^{1} \cdot$ Grethe Månum $^{1}$
}

Received: 16 August 2018 / Revised: 4 February 2019 / Accepted: 5 February 2019

(c) International Spinal Cord Society 2019

\begin{abstract}
Study design Single-subject design, standard training ("B") compared with Robotic training ("C").

Objectives To explore the impact of robotic training on upper limb function, activities of daily living (ADL) and training experience in subacute tetraplegic inpatients.

Setting Inpatient subacute Norwegian spinal cord injury (SCI) unit.

Methods Four participants (C4-7, AIS A-C) completed 11 sessions of robotic training using a passive robotic exoskeleton (Armeo Spring ${ }^{\circledR}$ ). Descriptive statistics and visual analyses were used for comparing standard occupational therapy and robotic training. Outcome measures included the Spinal Cord Independence Measure (SCIM-III), the Graded Redefined Assessment of Strength Sensibility and Prehension (GRASSP), and a questionnaire.

Results All of the participants exhibited an increase in assessments of upper limb function (GRASSP-total) right side $(0.4 \%-61.2 \%)$, and all except for one participant $(-8 \%)$ showed an increase on their left side $(20.9 \%-106.2 \%)$. Three out of four participants had improvements in ADL function SCIM-III (ranging from 5.6\% to 46.7\%). Results demonstrated improvements during the robotic intervention period in five out of 28 measurements. The participants enjoyed the exercise, and found it motivating and relevant to their injury (median ranged from 3.5 to 6.5 on a $0-7$ scale).

Conclusions Three out of four participants improved upper limb function and ADL independence, but the study could not confirm that improvements were due to the robotic intervention. The participants enjoyed the robotic training and found it relevant to their injury.
\end{abstract}

\section{Introduction}

Since the ability to control one's upper limbs is closely related to the level of independence and quality of life, restoration of the best-possible arm and hand function is essential following a cervical spinal cord injury (SCI) [1-3].

There is increasing evidence that motivating, intensive, and repetitive training can improve upper limb function after SCI [4, 5]. However, due to cost, as well as the monotony of hours of repetitive movements, therapists are

Supplementary information The online version of this article (https:// doi.org/10.1038/s41394-019-0170-3) contains supplementary material, which is available to authorized users.

Linda Sørensen

Linda.sorensen@sunnaas.no

1 Sunnaas Rehabilitation Hospital, Bjørnemyr, Norway limited in their ability to provide patients with motivating intensive training [6-8].

Robotic therapy has been suggested as a tool to provide patients with more repetitions [6]. The virtual reality aspect of robotic therapy simulates real-life activities, provides encouraging feedback, and might motivate patients to endure more repetitions. Furthermore, such training might, according to the principles of motor learning, lead to improved functional outcomes [9].

There have been several studies examining the functional outcomes of robotic training compared with the conventional training of the upper extremities [10-13]. In a Cochrane review by Mehrholz et al. [13], 34 trials of persons with stroke receiving robotic training were included. The persons receiving robot-assisted therapy were more likely to improve their ADL, arm strength, and arm function than the control groups that received conventional therapy.

Only a few studies have examined upper limb robotic training in SCI. Vanmulken et al. [7] found the Haptic master, which provides either active or passive support, to 
be feasible and safe in five persons with chronic SCI. Zariffa et al. [6] examined the feasibility and efficacy for the Armeo Spring, an exoskeleton providing passive antigravity support. This study showed that patients in the subacute phase were motivated by the exercises, that the system was easy to use, and helpful for providing feedback on progress, but compared with control results, no functional improvements were detected. Cortes et al. [14] found the InMotion wrist robot to be feasible, safe, and associated with significant results for motor performance in 10 persons with chronic SCI. Kim et al. [15] found some improvements in strength and independence, but not significant, in a group of SCI inpatients. Other studies, all case studies, have found similar systems (e.g., the Mahi Exo II, the Rice Wrist and the ReoGo) to be feasible, safe, and exhibit some functional improvements [16-18]. Although feasibility and safety seem to be established, there is still a dearth of studies on the effect of upper limb robotics on persons with SCI in the subacute phase. Thus, this study aimed to explore the effect of a robotic training program on arm, hand, and ADL function, as well as patient experience in subacute tetraplegic inpatients.

\section{Methods}

\section{Study design}

We applied a B-C-B single-subject design (SSD) for a six -week study period ( $\mathrm{B}^{1}$ for two weeks, $\mathrm{C}$ for two weeks, and $\mathrm{B}^{2}$ for two weeks). The single-subject design was chosen as it allows study participants to be their own controls, which makes the method suitable when withdrawing standard rehabilitation is considered inexpedient [19].

"B" represents the baseline when the participants received occupational therapy. Standard occupational therapy was then withdrawn and replaced with the robotic intervention period ("C") consisting of 11 sessions of robotic training, each lasting $60 \mathrm{~min}$. This was followed by a second "B" period of standard occupational therapy. All of the participants were assessed six times; three times during the first "B" period, twice during the robotic intervention period " $\mathrm{C}$ ", and once during the last " $\mathrm{B}$ " period. The assessments and intervention were carried out at Sunnaas Rehabilitation Hospital by four trained and experienced therapists. The assessors were not blinded to which phase the participants were in during the study. The study was approved by the Commissioner for Protection of Privacy in Research and the Regional Committee for Medical and Health Research Ethics South East in Norway. All of the participants volunteered, and we obtained informed consent from each participant.

\section{Participants}

During the inclusion period of five months, four out of five possible subacute inpatients were successively included. The inclusion criteria was complete or incomplete, traumatic or nontraumatic cervical SCI, American Spinal Injury Association (ASIA) Impairment Scale (AIS) A-C [20], age at least 18 years or older, the ability to sit upright for $60 \mathrm{~min}$, the ability to understand instructions, and the physical, cognitive, and behavioral capability to comply with the intensive training program.

\section{Robot-training protocol}

The participants were scheduled for four one-hour sessions of robot-training per week for two and a half weeks. Both arms were trained during each session.

\section{Armeo Spring system}

Armeo Spring is a mechanical arm orthosis/exoskeleton with spring mechanisms, which uses gravity support to enable persons to perform virtual reality activities in a twoor three-dimensional game environment, where grippressure sensors detect the person's grip strength [6]. The virtual reality games train persons to reach in different directions, perform more precise movements, and grip. The therapist calibrates a patient's workspace based on his or her functional ability, and the exoskeleton supports naturalistic movements in the shoulder, elbow, wrist, and finger flexion [6].

\section{Robotic setup}

The participants were placed in front of a height-adjustable table with a computer screen, sitting in their own wheelchair (Fig. 1). Their arm was placed into the exoskeleton, attached with straps and adjusted in size.

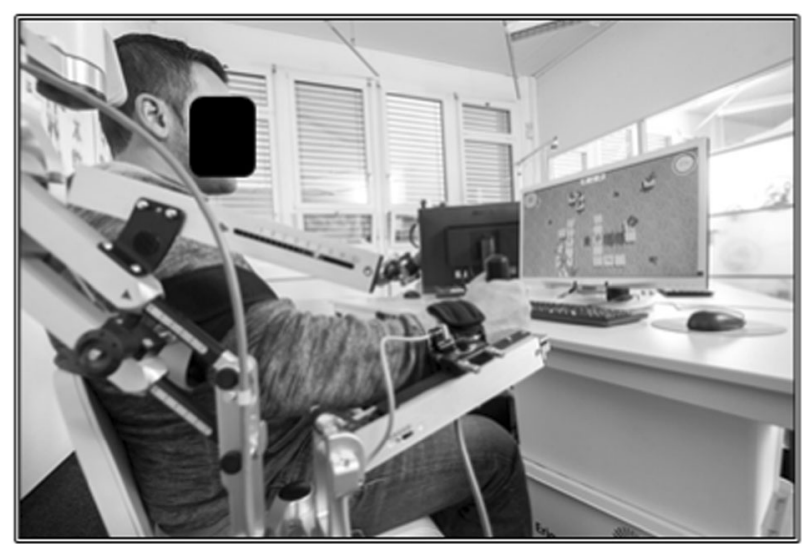

Fig. 1 Armeo Spring set up. Picture by Hocoma ${ }^{\circledR}$ 
During the first session, the weight support was set by the therapist, so the participant's arm was in a horizontal position with approximately a $45^{\circ}$ flexion in the shoulder and a $25^{\circ}$ flexion in the elbow. Games that were considered to be relevant for training upper limb function in tetraplegia were selected. During the robotic training, the therapist adjusted the weight support and level of difficulty of the games to ensure that the training remained challenging.

During the robotic intervention period, the participants did not receive other occupational therapy. They did, however, receive physiotherapy sessions as part of their rehabilitation process. Standard occupational therapy, as provided during the baseline period "B", consisted of 45min sessions, four times per week: strength exercises with weights or manual resistance for all of the active muscles in the upper extremities, grip training (mainly practicing the tenodesis grasp) or ADL training (e.g., practicing drinking, eating, dressing, upper toilet, and wheelchair maneuvering).

\section{Measurements}

\section{Arm and hand function}

The Graded Redefined Assessment of Strength Sensibility and Prehension (GRASSP) is a multimodal upper extremity test, consisting of five subtests; strength on 10 selected upper extremity muscles, sensibility, grasping, and functional tasks (prehension). The test was developed for patients with cervical SCI [21].

\section{Activities of daily living}

We assessed ADL using the Spinal Cord Independence Measure III (SCIM-III). The SCIM-III measures persons with SCI's respiration/sphincter function and ability to perform self-care and mobility, independently [22]. Seventeen questions are rated from totally dependent to totally independent with a maximum total score of 100 .

\section{Participants training experience}

All of the participants provided feedback about their experience using the Armeo Spring in a 13-item questionnaire developed by Zariffa et al. for a similar study [6]. The answers ranged from 1 (Disagree strongly) to 7 (Agree strongly) on a seven-point Likert scale.

\section{Data analysis}

The data were analyzed by descriptive statistics and visual analyses.

Mean shift (i.e., the percentage mean change between the baseline results and the robotic intervention) was calculated, and data were visually analyzed for trends and overlaps [23]. Microsoft Excel was used to prepare line graphs and trendlines. Overlap lines were inserted manually. The trend, which refers to the rise or fall pattern of the data during the baseline and the robotic intervention periods, was noted with a minus sign for falling or a plus sign when rising (supplementary table 2). A straight line was inserted at the lowest and highest score in the baseline to investigate numbers of overlap. If there was: (1) a positive change in the mean (2) a positive change in trend and (3) if two data points in the robotic intervention period were positively outside the range of baseline scores (overlap), it was concluded that the change was due to the robotic intervention. This change will be referred to as clinically significant change, as suggested by Zahn and Ottenbacher [24, 25]. Results of the participant questionnaire are reported in median and range.

\section{Results}

\section{Participant characteristics}

As shown in Table 1, the participants were all men between 19- and 62-years-old; the number of days since injury varied between 32 and 107. All of the participants completed the six-week study period with 11 sessions of robot-training, except for one participant 2 that completed nine sessions. No adverse symptoms were reported. The effective training time varied between 28 and 42 min per session (for both arms). Participant 1 and 3 had no passive or active grasp and were unable to perform either of the prehension tasks.

\section{Change in arm and hand function}

\section{GRASSP total score}

All of the participants exhibited improvements on their right side $(0.4 \%$ to $61.2 \%)$ (Fig. 2).

Three participants exhibited improvements on the left side $(20.9 \%-106.2 \%)$. One participant 3 showed a positive change in both trendlines and overlap; he was therefore

Table 1 Patient characteristics

\begin{tabular}{llllll}
\hline Participant & Age & $\begin{array}{l}\text { Motor } \\
\text { level }\end{array}$ & $\begin{array}{l}\text { AIS } \\
\text { grade* }\end{array}$ & $\begin{array}{l}\text { Days } \\
\text { since } \\
\text { injury }\end{array}$ & $\begin{array}{l}\text { Total effective } \\
\text { Robot-training } \\
\text { h min }\end{array}$ \\
\hline 1 & 26 & C5/C6 & A & 107 & 7.43 \\
2 & 19 & C6/C7 & A & 32 & 4.58 \\
3 & 62 & C4 & C & 64 & 5.14 \\
4 & 32 & C6 & A & 68 & 5.42 \\
\hline
\end{tabular}

*American Spinal Cord Injury

Association Impairment Scale 


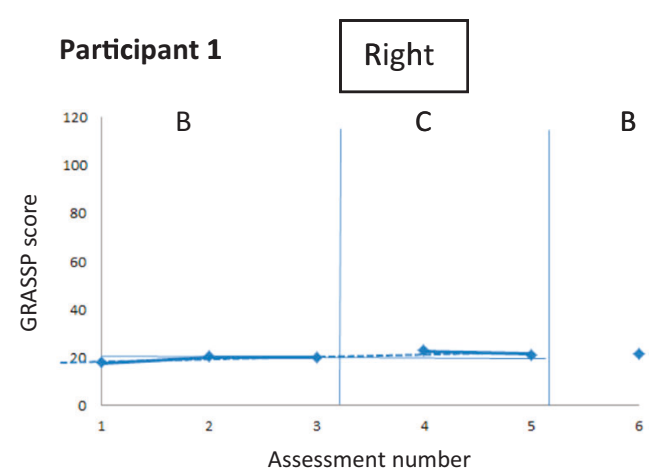

\begin{tabular}{ll} 
Participant $2 \quad$ Right \\
\cline { 2 - 2 }
\end{tabular}
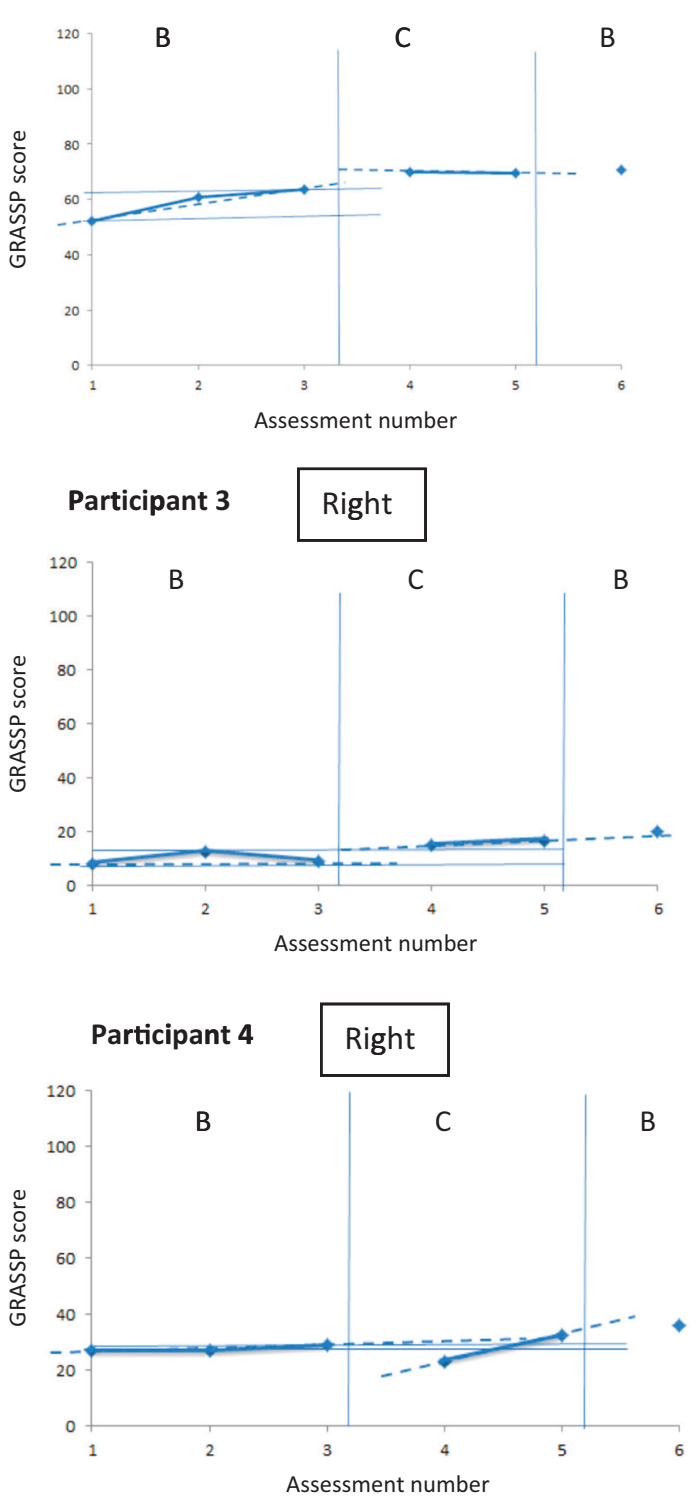

Fig. 2 Total score for Graded Redefined Assessment of Strength Sensibility and Prehension (GRASSP) for patient 1-4 right and left hand, with trendlines (dotted line) and overlap lines inserted.
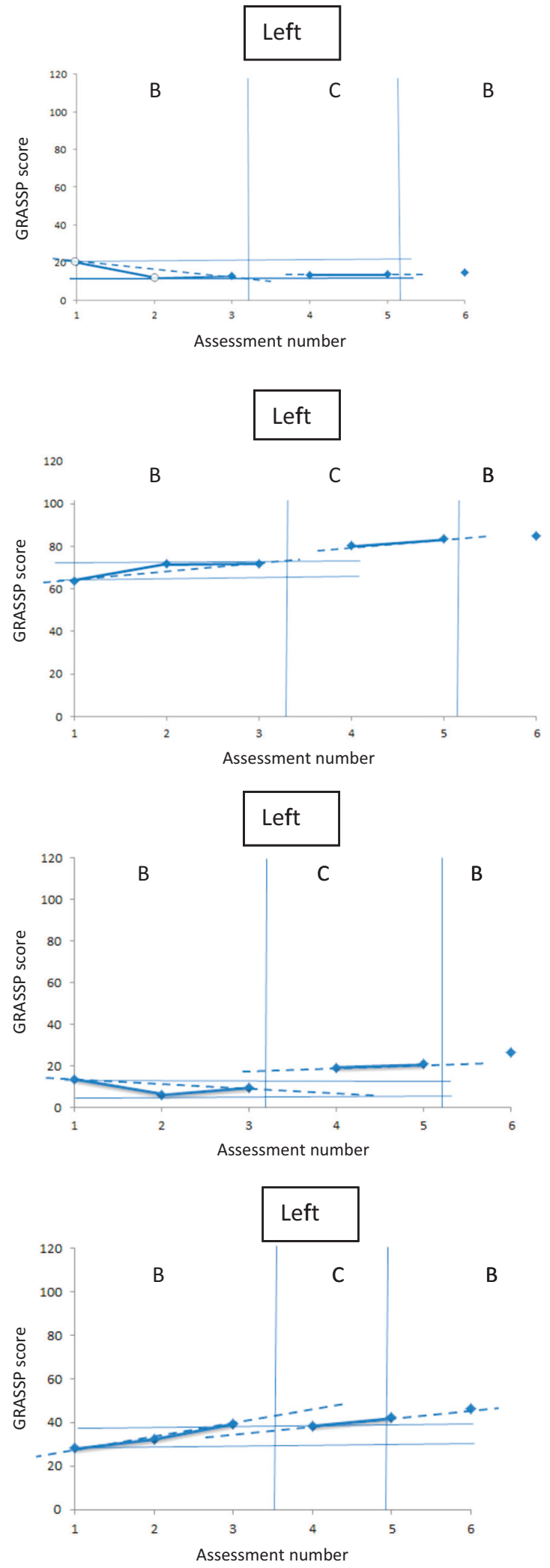

Maximum score is 116 . The " $\mathrm{B}$ " represents the standard occupational therapy phases and " $\mathrm{C}$ " the robotic-intervention period 
Table 2 Graded Redefined Assessment of Strength, Sensibility and Prehension (GRASSP)—Strength

\begin{tabular}{|c|c|c|c|c|}
\hline Participant & 1 & 2 & 3 & 4 \\
\hline \multicolumn{5}{|c|}{ Mean (SD) baseline } \\
\hline -right & $12.2(0.3)$ & $23.8(1.8)$ & $9.2(1.3)$ & $11.0(0)$ \\
\hline -left & $12.3(0.6)$ & $24.5(0.5)$ & $8.7(3.3)$ & $13.2(0.6)$ \\
\hline \multicolumn{5}{|c|}{ Mean $(S D)$ robot-training } \\
\hline -right & $13.0(0)$ & $27.0(0)$ & $13.3(1.8)$ & $11.5(0.7)$ \\
\hline -left & $13.8(0.4)$ & $32.0(0.7)$ & $15.5(4.9)$ & $14.4(0.7)$ \\
\hline \multicolumn{5}{|c|}{ Mean shift \% } \\
\hline -right & 6.6 & 13.4 & 44.6 & 4.5 \\
\hline -left & 12.2 & 30.6 & 78.2 & 9.0 \\
\hline \multicolumn{5}{|c|}{ Mean post robot-training } \\
\hline -right & 13.5 & 25.0 & 18.0 & 13.5 \\
\hline -left & 14.5 & 36.0 & 22.5 & 17.0 \\
\hline \multicolumn{5}{|c|}{ Change from robot-training $\%$} \\
\hline -right & 3.8 & -7.4 & 35.3 & 17.4 \\
\hline -left & 5.0 & 12.5 & 45.2 & 18.0 \\
\hline \multicolumn{5}{|l|}{ Trend } \\
\hline -right & - & - & + & + \\
\hline -left & - & - & + & + \\
\hline \multicolumn{5}{|l|}{ Overlap } \\
\hline -right & + & + & + & - \\
\hline -left & + & + & + & - \\
\hline
\end{tabular}

Subtest Manual Muscle test for 10 selected muscles rated 0-5; total score 50

Trend + indicates a positive change in trendline from baseline (" $\mathrm{B}$ ") to intervention period ("C")

Overlap + indicates that both assessments points in the intervention period are positively outside range of baseline

considered to have clinically significant changes bilaterally. Results in terms of the trendline directions and overlap are shown in Fig. 2.

\section{Manual muscle test}

The results are shown in Table 2. All of the participants exhibited bilateral improvement ranging from $4.5 \%$ to $44.6 \%$ on their right side, and $9.0 \%$ to $78.2 \%$ on their left sides. Participant 4 attained clinical significance on his left side with a positive change in mean shift, trendline, and overlap. Participant 3 fulfilled the criteria for a clinically significant change bilaterally.

\section{Sensibility, Semmes Weinstein Monofilaments (SMW)}

The results are shown in Table 3. Two participants exhibited improvements on their right side, and two participants exhibited improvements on their left sides. None of the participants fulfilled the criteria for a clinically significant change in sensibility.
Table 3 Graded Redefined Assessment of Strength, Sensibility and Prehension (GRASSP)—Sensibility

\begin{tabular}{|c|c|c|c|c|}
\hline Participant & 1 & 2 & 3 & 4 \\
\hline \multicolumn{5}{|c|}{ Mean (SD) baseline } \\
\hline -right & $7.3(-1.2)$ & $23.3(1.2)$ & $0.7(1.2)$ & $10.0(1)$ \\
\hline -left & $2.7(4.6)$ & $23.3(1.2)$ & $1.3(0.6)$ & $8.3(2.3)$ \\
\hline \multicolumn{5}{|c|}{ Mean $(S D)$ robot-training } \\
\hline -right & $9.0(1.4)$ & $23.0(0)$ & $2.0(0)$ & $7.0(1.4)$ \\
\hline -left & $0.0(0)$ & $22.5(0.7)$ & $3.0(1.4)$ & $10.0(2.6)$ \\
\hline \multicolumn{5}{|c|}{ Mean shift \% } \\
\hline -right & 23.3 & -1.3 & 185.0 & -30.0 \\
\hline -left & -100.0 & -3.4 & 131.0 & 20.5 \\
\hline \multicolumn{5}{|c|}{ Mean post robot-training } \\
\hline -right & 8.0 & 22.0 & 2.0 & 9.0 \\
\hline- left & 0.0 & 24.0 & 4.0 & 12.0 \\
\hline \multicolumn{5}{|c|}{ Change from robot-training $\%$} \\
\hline -right & -11.0 & -4.3 & 0.0 & 28.6 \\
\hline -left & 0.0 & 6.7 & 33.3 & 20.0 \\
\hline \multicolumn{5}{|l|}{ Trend } \\
\hline -right & - & - & - & + \\
\hline -left & - & - & - & - \\
\hline \multicolumn{5}{|l|}{ Overlap } \\
\hline -right & - & - & - & - \\
\hline -left & - & - & - & - \\
\hline
\end{tabular}

Subtest Semmes Weinstein Monofilaments for dorsal and palmar sensibility (summed) with a total score of 24

Trend + indicates a positive change in trendline from baseline ("B") to intervention period ("C")

Overlap + indicates that both assessments points in the intervention period are positively outside range of baseline

\section{Prehension ability and performance}

The results of the prehension tests are listed in Table 4.

Participant 2 showed improvements on his right side and a decrease in his left-side prehension ability. Participant 4 exhibited bilateral improvement with a clinically significant change on his right side.

Both participants exhibited bilaterally improvements ranging from $17 \%$ to $71 \%$ on prehension performance. Participant 2 had positive changes on his trendlines and overlap, and therefore his changes were considered to be clinically significant on his left side. Participant 4 attained clinical significance on his right side.

\section{Changes in activities of daily living}

The results are listed in Table 5. All of the participants, except for one, exhibited improvements, ranging from $5.6 \%$ to $46.7 \%$.

None of the participants fulfilled the criteria for clinically significant changes in ADL independence. 
Table 4 Graded Redefined Assessment of Strength, Sensibility and Prehension (GRASSP)—Prehension

\begin{tabular}{|c|c|c|c|c|}
\hline \multirow[b]{2}{*}{ Participant } & \multicolumn{2}{|c|}{ Prehension ability } & \multicolumn{2}{|c|}{ Prehension performance } \\
\hline & 2 & 4 & 2 & 4 \\
\hline \multicolumn{5}{|c|}{ Mean (SD) baseline } \\
\hline -right & $4.3(1.2)$ & $2.0(0)$ & $7.3(2)$ & $4.7(0.6)$ \\
\hline -left & $9.0(0)$ & $4.0(0)$ & $12.3(3.8)$ & $7.7(2.5)$ \\
\hline \multicolumn{5}{|c|}{ Mean $(S D)$ robot-training } \\
\hline -right & $7.3(0.4)$ & $3.3(0.4)$ & $12.5(0.7)$ & $5.5(3.5)$ \\
\hline -left & $8.3(1)$ & $4.5(0)$ & $19.5(3.5)$ & $10.0(2.8)$ \\
\hline \multicolumn{5}{|c|}{ Mean shift \% } \\
\hline -right & 69.8 & 65.0 & 71.0 & 17.0 \\
\hline -left & -7.8 & 12.5 & 58.5 & 29.9 \\
\hline \multicolumn{5}{|c|}{ Mean post robot-training } \\
\hline -right & 8.5 & 4.5 & 13.0 & 9.0 \\
\hline -left & 9.0 & 4.5 & 18.0 & 14.0 \\
\hline \multicolumn{5}{|c|}{ Change from robot-training \% } \\
\hline -right & 16.4 & 36.4 & 4.0 & 63.6 \\
\hline -left & 8.4 & 0.0 & -7.7 & 40.0 \\
\hline \multicolumn{5}{|l|}{ Trend } \\
\hline -right & - & + & - & + \\
\hline -left & - & - & + & - \\
\hline \multicolumn{5}{|l|}{ Overlap } \\
\hline -right & + & + & + & - \\
\hline -left & - & + & + & - \\
\hline
\end{tabular}

Subtest prehension: (a) ability: grip ability total score 12, (b) performance: functional task total score 30

Trend + indicates a positive change in trendline from baseline ("B") to intervention the period ("C")

Overlap + indicates that both assessments points in the intervention period are positively outside range of baseline

\section{Participant training experience}

As demonstrated by the data in Table 6, the participants reported satisfaction with using the Armeo Spring. The results revealed that they found the training to be relevant for their type of injury, easy to understand, and that it motivated them to perform the exercises. However, only one participant preferred the robotic training to conventional occupational therapy. The participant, who initially had markedly higher scores on both upper limb function and ADL independence than the other three participants, had the lowest scores on the participant experience questionnaire.

This study demonstrated improvements in arm and hand function and ADL in three out of four participants. However, in only one of the participants 3 did the results suggest that the improvements were caused by the robotic training.
Table 5 Activities of daily living: Spinal Cord Independence Measure III

\begin{tabular}{lclll}
\hline Participant & 1 & 2 & 3 & 4 \\
\hline Mean (SD) baseline & $18.0(1.7)$ & $26.3(0.6)$ & $17.0(0)$ & $16.7(2.9)$ \\
Mean(SD) robot-training & $19.0(0)$ & $29.5(0.7)$ & $17.0(0)$ & $24.5(6.4)$ \\
Mean shift \% & 5.6 & 12.2 & 0.0 & 46.7 \\
Mean post robot-training & 19.0 & 36.0 & 20.0 & 29.0 \\
Change from & 0.0 & 22.0 & 17.6 & 18.4 \\
robot-training \% & & & & \\
Trend & - & - & - & + \\
Overlap & - & + & - & - \\
\hline
\end{tabular}

Total score 100

Trend + indicates a positive change in trendline from baseline ("B") to intervention period ("C")

Overlap + indicates that both assessments points in the intervention period are positively outside range of baseline

\section{Discussion}

In this study, upper limb robotic training was provided and compared to standard occupational therapy, in four patients with cervical spinal cord injury.

All of the participants exhibited improvements in the GRASSP subtest measuring muscle strength. Participant 2 and 4, who had some preserved hand function compared with the other participants, showed larger improvements (13-78\%) than the participants without the ability to grip. This supports the results of Zariffa et al., who found significant improvements in GRASSP strength in a cervical SCI subacute subgroup with some restored hand function [6]; these authors concluded that Armeo Spring training might have been more suitable for this patient subgroup [6].

Motivation is essential for patients to be encouraged in therapy to attain short-term and long-term goals towards independence. Providing useful and enjoyable training can make it easier for patients to attain these goals. Robotic training with elements from virtual reality has been shown to be a powerful tool to motivate patients to perform repetitive movements [9]. In the present study, three out of four participants rated their enjoyment of and motivation to use Armeo training as high (median 5.5-7). Of these only one patient attained clinically significant results, suggesting that robotic therapy was the cause of the improvement. These results are similar to those of Zariffa et al. [6] and Vanmulken et al. [7]. One of the participants did not rate the Armeo training as enjoyable 2. He stated that he found the Armeo to restrict rather than facilitate his shoulder and elbow range of motion. This situation might persist for some persons with tetraplegia who have normal strength and range of motion in the elbow and shoulder. 
Table 6 Motivation and experience

\begin{tabular}{|c|c|c|c|c|c|c|}
\hline Participant & 1 & 2 & 3 & 4 & Median & Range \\
\hline Q1. The ARMEO was enjoyable to use. & 6 & 3 & 6 & 5 & 5.5 & $3-6$ \\
\hline Q2. It was easy to understand how to use the ARMEO. & 6 & 7 & 6 & 7 & 6.5 & $6-7$ \\
\hline Q3. The games increased your motivation to perform your exercises. & 6 & 4 & 5 & 7 & 5.5 & $4-7$ \\
\hline $\begin{array}{l}\text { Q4. You would be comfortable using the ARMEO with only minimal } \\
\text { supervision by a therapist. }\end{array}$ & 7 & 4 & 2 & 7 & 5.5 & $2-7$ \\
\hline $\begin{array}{l}\text { Q5. You felt that the ARMEO training was as effective for rehabilitation as } \\
\text { your usual rehabilitation sessions with a therapist. }\end{array}$ & 7 & 4 & 4 & 5 & 4.5 & $4-7$ \\
\hline Q6. The ARMEO was helpful for tracking the progress of your rehabilitation. & 7 & 7 & 5 & 5 & 6 & $5-7$ \\
\hline Q7. The length of the sessions was appropriate. & 7 & 4 & 6 & 7 & 6.5 & $4-7$ \\
\hline Q8. The number of sessions per week was appropriate. & 6 & 3 & 6 & 5 & 5.5 & $3-6$ \\
\hline $\begin{array}{l}\text { Q9. You felt that the ARMEO exercises were more relevant to activities in } \\
\text { your daily life than conventional rehabilitation. }\end{array}$ & 6 & 1 & 5 & 5 & 5 & $1-6$ \\
\hline Q10. You would use the ARMEO in your free time if it was available to you. & 7 & 1 & 5 & 3 & 4 & $1-7$ \\
\hline Q11. You preferred the ARMEO training to conventional rehabilitation. & 5 & 4 & 3 & 3 & 3.5 & $3-5$ \\
\hline Q12. The ARMEO is appropriate for someone with your level of lesion. & 7 & 5 & 6 & 7 & 6.5 & $5-7$ \\
\hline $\begin{array}{l}\text { Q13. The ARMEO is appropriate for someone with your type of injury (that } \\
\text { is, AISI A, B, C or D). }\end{array}$ & 7 & 5 & 6 & 7 & 6.5 & $5-7$ \\
\hline 1: Disagree strongly to 7 : Agree strongly. & & & & & & \\
\hline
\end{tabular}

Most patients did not prefer robotic training to their usual exercises with the therapist. We experience that patients enjoy human interaction during training sessions, which suggests that there should be a variety in upper limb training, including both standard occupational therapy and robotic training.

The lack of clinically significant changes in this study might be due to an insufficient amount of training. This study aimed to explore the effect on arm, hand, and ADL function by providing an intensive training program using robotics. However, the active training time during the robotic sessions was less than expected. Setting up the system, and changing it from one arm to another, decreased the amount of time that the participants were actively engaged. In the future we hope for systems with a more user-centered design, which enables a faster set up time, as suggested by Singh et al. [26]. The amount of time of active movement during the 45-min sessions of standard occupational therapy was not noted, but clinical experience reveals that delivering a high number of repetitions via standard occupational therapy activities is challenging. In a study by Lang et al., participants attained a mean of 32 functional repetitions during standard occupational therapy sessions lasting $36 \pm 14 \mathrm{~min}$ [27]. Zbogar et al. found similar results with 31 repetitions for upper limb exercises in the subacute phase for persons with tetraplegia [4]. The amount of repetitions reported in robotic training is above 1000 repetitions [28]. These findings indicate that even though the amount of robotic training was less than what we hoped for, it is likely that it included more repetitions than provided by standard occupational therapy. The results of Hsieh et al. support implementing more repetitive training, which can be delivered by robotic systems to enhance functional outcomes [28].

In a clinical setting, it could be possible to provide patients with more sessions per day if the clinic had two or three robots. Clinics such as Kliniken Valens, Rehaklinik Zihlschlacht - both in Switzerland and Schön Klinik in Germany have all set up their upper limb robotic equipment, so that one therapist can assist up to three patients at a time.

Three of the participants exhibited an increase in SCIMIII-ADL independence. However, since the improvements were caused by a change from manual to an electric wheelchair and change in breathing assistance, it is unlikely that the improvements were related to the robotic intervention.

The SSD has been said to be ideally suited to investigate treatment effects in rehabilitation research [24, 25]. However, the requirement of a stable baseline prior to the introduction of the robotic intervention represents a challenge in the primary/subacute SCI rehabilitation setting. According to Ditunno [29], persons with cervical SCI normally regain one level on the AIS scale within the first year after injury. This process of natural recovery might lead to increased arm and hand function without intervention, which could have influenced the results of this study.

In the present study, it was not possible to fulfill all of the prerequisites of an SSD. A minimum of three data points is considered to be necessary to determine the subject's performance pattern. The assessments took approximately two hours to perform. During the study period, the participants stated that they found it difficult to understand the necessity 
of the testing, which they found exhausting. This situation was particularly true for the participants who struggled to perform the prehension tests. In the GRASSP manual, the possibility of using GRASSP without the prehension tasks are suggested for the participants in the early subacute phase. If this version had been used it might have made it possible to expose the participants to more tests and thereby collect more data during the robotic intervention period. Three or more data points in each phase would have been better in exploring whether the changes were due to the intervention or to natural recovery.

Also, a disadvantage of the SSD is that there are few participants and no control group, which limits the generalizability of the findings.

However, this study supplements the limited number of studies in the literature concerning robotic upper limb training in persons with cervical SCI. There have been several studies confirming the feasibility and safeness of robotic training, but only a few studies have reported on its functional outcomes. More studies are needed to establish a guideline on robotic upper limb training in persons with cervical SCI.

\section{Conclusion}

Here we show that our participants exhibited improvements in upper limb function, strength, and ADL independence. No improvements were found in sensibility. The improvements associated with robotic therapy presented in this and similar studies appear to be similar to the functional outcomes derived from standard upper limb training. Robotic training can provide a high number of repetitions, and persons rate such training as being motivating and enjoyable. Providing robotic training for upper limb function might be an encouraging supplemental treatment to standard training in rehabilitation hospitals for persons with cervical SCI.

Acknowledgements We acknowledge the help of Eva Denison, Department of Physiotherapy, Faculty of Health Sciences, OsloMet University, Norway.

Funding Equipment (Armeo Spring ${ }^{\circledR}$ ) was provided by Sunnaas Foundation. The project had no other support or funding. The intervention was carried out by therapists working at the Sunnaas rehabilitation hospital and participants were admitted patients.

\section{Compliance with ethical standards}

Conflict of interest The authors declare that they have no conflict of interest.

Publisher's note: Springer Nature remains neutral with regard to jurisdictional claims in published maps and institutional affiliations.

\section{References}

1. Harvey L. Management of Spinal Cord Injuries. A guide for physiotherapists. USA: Churchill Livingstone Elsevier; 2008:93-105.

2. Anderson K. Targeting recovery: Priorities of the spinal cordinjured population. J Neurotrauma. 2004;21:1371-83.

3. Snoek GJ, Jzerman MJ, Hermens HJ, Maxwell D, BieringSorensen F. Survey of the needs of patients with spinal cord injury: impact and priority for improvement in hand function in tetraplegics. Spinal Cord. 2004;42:526-32.

4. Zbogar D, Eng JJ, Miller WC, Krassioukov AV, Verrier MC. Movement repetitions in physical and occupational therapy during spinal cord injury rehabilitation. Spinal Cord. 2017;52:172-9.

5. Beekhuizen KS, Field-Fote EC. Sensory stimulation augments the effects of massed practice training in persons with tetraplegia. Arch Phys Med Rehabil. 2008;89:602-8.

6. Zariffa J, Kapadia N, Kramer JL, Taylor P, Alizadeh-Meghrazi M, Zivanovic V, et al. Feasibility and efficacy of upper limb robotic rehabilitation in a subacute cervical spinal cord injury population. Spinal Cord. 2012;50:220-6.

7. DAMM Vanmulken, AIF Spooren, HMH Bongers, HAM Seelen. Robot-assisted task-oriented upper extremity skill training in cervical spinal cord injury: a feasibility study. Spinal Cord. 2015;53:547-51.

8. Lozano-Quilis JA, Gil-Gomez H, Gil-Gomez JA, Albiol-Perez S, Palacios-Navarro G, Fardoun HM, et al. Virtual rehabilitation for multiple sclerosis using a kinect-based system: randomized controlled trial. JMIR Serious Games. 2014;2:e12.

9. Holden MK. Virtual environments for motor rehabilitation: review. Cyberpsychol Behav. 2005;8:187-211.

10. Housman SJ, Scott KM, Reinkensmeyer DJ. A randomized controlled trial of gravity-supported, computer-enhanced arm exercise for individuals with severe hemiparesis. Neurorehabil Neural Repair. 2009;23:505-14.

11. Meadmore KL, Hughes AM, Freeman CT, Cai Z, Tong D, Burridge $\mathrm{JH}$, et al. Functional electrical stimulation mediated by iterative learning control and 3D robotics reduces motor impairment in chronic stroke. J Neuroeng Rehabil. 2012;9:32.

12. da Silva Cameirao M, IBS Bermudez, Duarte E, Verschure PF. Virtual reality based rehabilitation speeds up functional recovery of the upper extremities after stroke: a randomized controlled pilot study in the acute phase of stroke using the rehabilitation gaming system. Restor Neurol Neurosci. 2011;29:287-98.

13. Mehrholz J, Pohl M, Platz T, Kugler J, Elsner B. Electromechanical and robot-assisted arm training for improving generic activities of daily living, arm function, and arm muscle strength after stroke. Cochrane Database Syst Rev. 2015;4:CD006876.

14. Cortes M, Elder J, Rykman A, Murray L, Avedissian M, Stampa A, et al. Improved motor performance in chronic spinal cord injury following upper-limb robotic training. Neuro Rehabil. 2013;33:57-65.

15. Kim J, Lee BS, Lee H, Cho D, Lim J, Kim J. et al. Clinical efficacy on upper limb robotic therapy in people with tetraplegia: a pilot randomized controlled trial. Spinal Cord. 2019;57:49-57.

16. Kadivar Z, Sullivan JL, Eng DP, Pehlivan AU, O'Malley MK, Yozbatiran N. et al. Robotic training and kinematic analysis of arm and hand after incomplete spinal cord injury: a case study. IEEE Int Conf Rehabil Robot. 2011;2011:5975429.

17. Siedziewski L, Schaaf RC, Mount J. Use of robotics in spinal cord injury: a case report. Am J Occup Ther. 2012;66:51-8.

18. Yozbatiran N, Berliner J, O’Malley MK, Pehlivan AU, Kadivar Z, Boake $\mathrm{C}$, et al. Robotic training and clinical assessment of upper extremity movements after spinal cord injury: a single case report. J Rehabil Med. 2012;44:186-8. 
19. Carter ER, Lubinsky J, Domholdt E. Rehabilitation Research. Principles and Applications. 4th ed. St. Louis. USA: Elsevier Saunders; 2011.

20. Burns S, Biering-Sørensen F, Donovan W, Graves DE, Jha A, Johansen M, Jones L, Krassioukov A, Kirshblum S, Mulcahey MJ, Read MS, Waring W. International Standards for Neurological Classification of Spinal Cord Injury, Revised 2011. Top Spinal Cord Inj Rehabil. 2012;18:85-99.

21. Kalsi-Ryan S, Beaton D, Curt A, Duff S, Popovic MR, Rudhe C, et al. The Graded Redefined Assessment of Strength Sensibility and Prehension: reliability and validity. J Neurotrauma. 2012;29:905-14.

22. Catz A, Itzkovich M, Agranov E, Ring H, Tamir A, et al. SCIM-spinal cord independence measure (version II): sensitivity to functional changes. Spinal Cord. 2001;39:97-100.

23. Idland G, Sylliaas H, Mengshoel AM, Pettersen R, Bergland A. Progressive resistance training for community-dwelling women aged 90 or older; a single-subject experimental design. Disabil Rehabil. 2014;36:1240-8.
24. Ottenbacher KJ. Visual inspection of single-subject data: an empirical analysis. Ment Retard. 1990;28:283-90.

25. Zhan S, Ottenbacher KJ. Single subject research designs for disability research. Disabil Rehabil. 2015;23:1-8.

26. Singh H, Unger J, Zariffa Z, Pakosh M, Jaglal S, Craven C, et al. Robot-assisted upper extremety rehabilitation for cervical spinal cord injuries: a systematic scoping review. Disabil Rehabil: Assist Technol. 2018;13:704-15.

27. Lang CE, Macdonald JR, Reisman DS, Boyd L, Jacobson Kimberley T, Schindler-Ivens SM, et al. Observation of amounts of movement practice provided during stroke rehabilitation. Arch Phys Med Rehabil. 2009;90:1692-8.

28. Hsieh YW, Wu CY, Liao WW, Lin KC, Wu KY, Lee CY. Effects of treatment intensity in upper limb robot-assisted therapy for chronic stroke: a pilot randomized controlled trial. Neurorehabil Neural Repair. 2011;25:503-11.

29. Ditunno JF. Predicting recovery after spinal cord injury: A rehabilitation imperative. Arch Phys Med Rehabil. 1999; 80:361-4. 